\title{
Knowledge Levels of Medical Students about Hand Hygiene Practices in a Tertiary Hospital, Bangalore
}

\author{
C. Bhavana*, Jyoti S. Kabbin and R. Ambica
}

Department of Microbiology, Bangalore Medical College and Research Institute, Bangalore, Karnataka, India

*Corresponding author

\section{A B S T R A C T}

\begin{tabular}{|c|c|}
\hline Keywords & \multirow{4}{*}{$\begin{array}{l}\text { Hand hygiene is the leading measure to reduce the incidence of health care associated infections (HAIs). } \\
\text { Although the techniques involved are simple, compliance is poor worldwide. This study was undertaken to } \\
\text { determine the level of knowledge on hand hygiene among medical students so that appropriate measures can be } \\
\text { taken to promote compliance. This study was conducted in Bangalore Medical College and Research Institute } \\
\text { from June to July } 2018 \text { among medical students using WHO hand hygiene questionnaire. } 78 \% \text { students had } \\
\text { received training in hand hygiene; everyone agreed it is necessary to be trained in hand hygiene practices. } 85 \% \\
\text { routinely used hand rub in patient care. } 33 \% \text { answered correctly that } 20 \text { s contact time; } 44 \% \text { answered } 3 \mathrm{ml} \text { as } \\
\text { minimal amount of alcohol-based hand rub essential to destroy the microorganisms. } 63 \% \text { and } 46 \% \text { of students } \\
\text { respectively had misconception that alcohol based hand rub causes dryness and more effective than hand wash. } \\
58 \% \text { thought hand rubbing and hand washing to be performed in sequence. } 9 \% \text { answered wrongly that hand } \\
\text { rubbing was the method required after visible exposure to blood. } 93 \% \text { have noticed that hand hygiene posters are } \\
\text { displayed at point-of-care. } 48 \% \text { were aware of NABH. The overall knowledge on hand hygiene practices was } \\
\text { moderate (363/557, } 65 \% \text { ). To conclude, it is essential to train the medical students in hand hygiene practices as it } \\
\text { helps in reducing HAIs }\end{array}$} \\
\hline $\begin{array}{l}\text { Hand hygiene, } \\
\text { Health care } \\
\text { associated } \\
\text { infections }\end{array}$ & \\
\hline Article Info & \\
\hline $\begin{array}{l}\text { Accepted: } \\
07 \text { February } 2019 \\
\text { Available Online: } \\
10 \text { March } 2019\end{array}$ & \\
\hline
\end{tabular}

\section{Introduction}

Health care-associated infections are a serious problem in health care services as they may cause prolonged hospital stay, high mortality, long-term disability, and excess health care costs. Most health care-associated infections can be transmitted from patient to patient via the hands of health care workers. In other words, hand hygiene is recognized as the leading measure to prevent cross-transmission of microorganisms and to reduce the incidence of health care associated infections (1).

Hand hygiene is a general term referring to any action of hand cleansing by using water and detergent and/or the use of alcohol-based hand sanitizers for the removal of transient microorganisms from hands (2). It is one of the least expensive and easy to train procedure which can substantially decrease these infections. Despite the relative simplicity of this procedure, compliance with hand hygiene among health care providers is as low as $40 \%(1,3,4)$.

Introduction of an evidence-based concept of "My five moments for hand hygiene" by World Health Organization has helped to address the problem to good extent. These five moments that call for the use of hand hygiene include the moment before touching 
a patient, before performing aseptic and clean procedures, after being at risk of exposure to body fluids, after touching a patient, and after touching patient surroundings. This concept has been effectively used to improve understanding, training, monitoring, and reporting hand hygiene among healthcare workers (5).

Numerous studies have shown that adherence to hand hygiene recommendations remains low and that improvement efforts frequently lack sustainability (6). This is may be due to several constraints such as heavy work load, high number of clinical procedures, and skin conditions of health care workers (7).

In developing countries, the prevalence of hand hygiene- associated infections has been found to be as high as $19 \%$. It is commonly observed that in a health care setup, nurses are the most compliant to the practice of hand hygiene; in contrast, the doctors are usually less compliant (8). In order to improve compliance of the doctor community, medical students ought to be sensitized with aspects of infection control during undergraduate level itself.

Despite these concepts have been emphasized, there has been lack in knowledge and practice of hand hygiene among the health care workers. Hence this study is undertaken to know the knowledge among the medical students regarding hand hygiene so that appropriate measures can be taken to train them and promote hand hygiene compliance.

\section{Materials and Methods}

This cross sectional and questionnaire based study was conducted in Bangalore Medical College and Research Institute from June 2018 to July 2018.A total of 557 medical students comprising of 396 undergraduates belonging to $4^{\text {th }}, 6^{\text {th }}$ and $8^{\text {th }}$ term, 52 interns and 109 postgraduates who were present at the time of the study were included. The purpose of the study was explained and informed consent was obtained. A WHO hand hygiene questionnaire comprising of 15 questions (Annexure) was distributed to each participant and asked to answer and return immediately. This Questionnaire comprised of 15 questions which included multiple choice and "yes" or "no" questions. Knowledge was assessed using WHO guidelines on Hand hygiene in health care (9). Each correct answer was given one point, and an incorrect answer zero. The maximum score obtainable for knowledge was 15 . The scores were calculated and expressed in percentage.

\section{Statistical analysis}

Data was analysed using Microsoft excel software. Descriptive statistics was used to calculate the percentage of each response given and associations between variables were tested using Chi- square test. The values were mentioned as mean \pm Standard Deviation (SD). A score of more than $75 \%$ was considered good, 50-74\% moderate and less than $50 \%$ as poor (10).

\section{Results and Discussion}

Overall 557 medical students were included in the study including $4^{\text {th }}$ term (147 students), $6^{\text {th }}$ term $(122$ students $), 8^{\text {th }}$ term (127 students), interns (52 students) and postgraduates (109 students).

Only $78 \%$ of the students had received formal training in hand hygiene.

Almost everyone agreed that it is necessary for them to be trained in hand hygiene practices as it prevents health care associated infections and agreed that observation of hand hygiene compliance is needed. 
$85 \%$ of the students routinely used alcohol based hand rub in the patient care.

Only $33 \%$ of the students answered correctly that 20 seconds contact time with an alcohol- based hand rub was essential to destroy most micro organisms, 39\% answered it to be 10 seconds, $23 \%$ answered it to be 1 minute and 5\% answered it to be 3 seconds.

$44 \%$ of the students answered that $3 \mathrm{~mL}$ was the minimum amount of alcohol- based hand rub required, $38 \%$ answered it to be $5 \mathrm{~mL}$, $15 \%$ answered $1 \mathrm{~mL}$ and $5 \%$ answered it to be $15 \mathrm{~mL}$.

$63 \%$ and $46 \%$ of the students respectively had misconception that alcohol based hand rub causes dryness and more effective than hand wash.
$58 \%$ of the students thought hand rubbing and hand washing are recommended to be performed in sequence.

9\% of the students answered wrongly that hand rubbing was the method required after visible exposure to blood.

93\% have noticed that hand hygiene posters are displayed at point-of-care as reminders.

Only $48 \%$ of students were aware of National Accreditation Board of Health (NABH).

The knowledge among the medical students regarding hand hygiene practices was moderate $(363 / 557,65 \%)$. Only $2 \%(11 / 557)$ had good knowledge. The overall scores of level of knowledge in the present study is depicted in Figure 1.

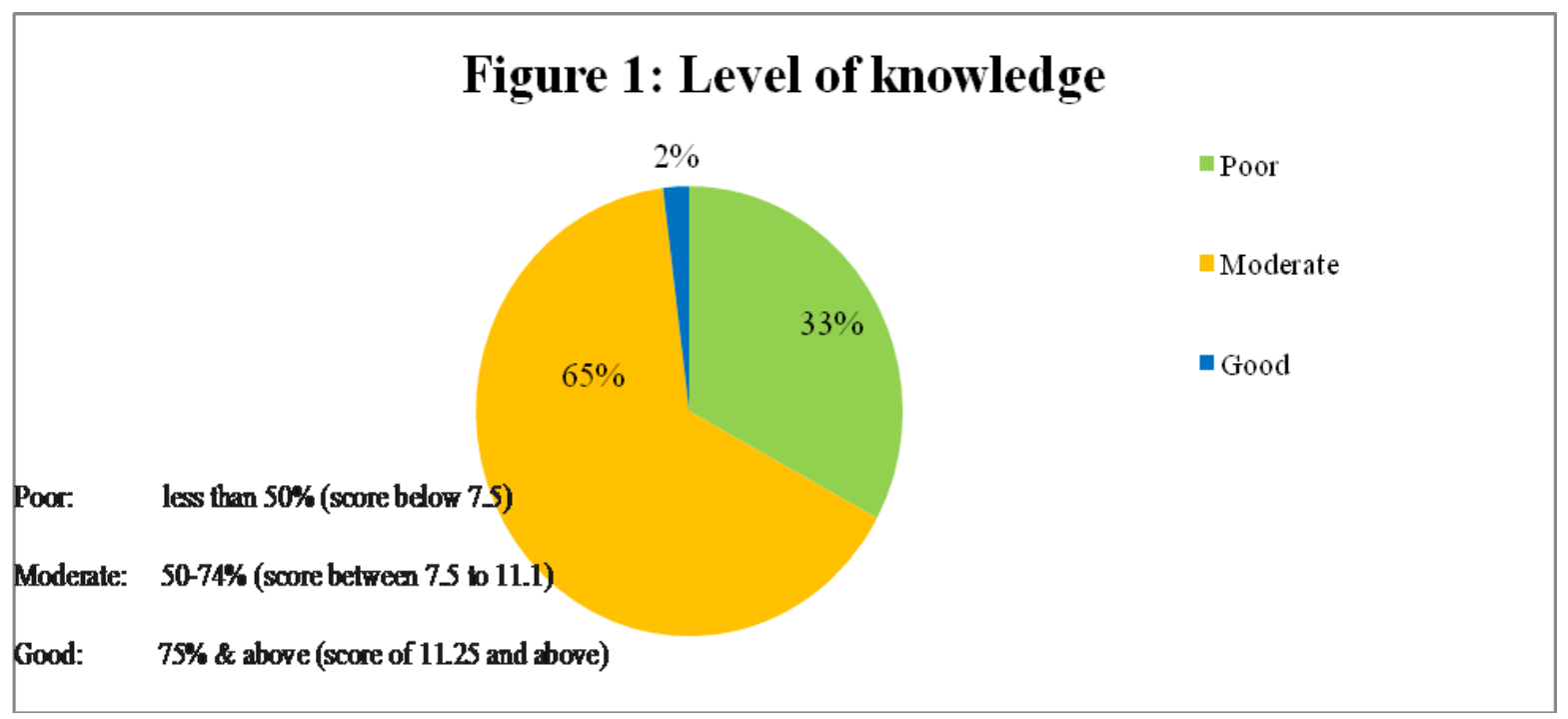

Hands are the main source of transmission of infections during healthcare. Hand hygiene is therefore the most important measure to avoid the transmission of harmful microbes and prevent healthcare-associated infections. Any healthcare worker involved in direct or indirect patient care needs to be concerned about hand hygiene and should be able to perform it correctly and at the right time.
In the present study, the level of knowledge about hand hygiene among the medical students was moderate (65\%), which was a positive finding. It was seen in accordance with the studies conducted by Nair et al., (10), Kamble et al.,(11), Nabavi et al., (12) among the medical students where the level of knowledge was moderate. 
Majority of medical students (78\%) had claimed to have received formal training on hand hygiene and almost everyone agreed that it is necessary for them to be trained in it, which is a good sign of awareness. In the studies by Nair et al., (10) and Kamble et al., (11) $79 \%$ and $84.5 \%$ of students whereas in Prabhakumar et al., (13) and Thakker et al., (14) only 40\% and $14.2 \%$ of students respectively had received formal training in hand hygiene practices.

The present study showed $85 \%$ of the students routinely used alcohol based hand rub compared to studies by Kamble VS et al., (11) where only $58.1 \%$ used hand rub.

In our study, only $33 \%$ and $44 \%$ respectively answered correctly that $20 \mathrm{~s}$ and $3 \mathrm{ml}$ as the minimal time and amount of hand rub required to destroy most of the micro organisms on hand. This was similar to the study conducted by Prabhakumar et al., (13), in which $29 \%$ and $48 \%$ students respectively answered both the questions right.

Majority of students (81\%) agreed that hand rubbing is more rapid than hand washing. Whereas, Modi et al., (15) reported only $61.4 \%$ students agreed for it. 63\% of students had misconception that alcohol based hand rub causes more dryness compared to hand washing which was similar to the study conducted by Kamble et al., (11). 54\% of students were aware that hand washing is more effective against micro organisms than hand rubbing in comparison with studies by Kamble et al., (11) and Modi et al., (15) (61.8\%).

$42 \%$ of students were aware that hand washing and hand rubbing are not recommended to be performed in sequence which was better than study by Kamble et al., (11) where only $21.8 \%$ students were aware of it. Majority of students $(91 \%)$ knew that hand washing is the required method following visible exposure to blood which was in accordance to majority of studies on hand hygiene.
Most of the students (93\%) agreed that observation of hand hygiene compliance is needed and they had observed that hand hygiene posters are displayed at point-of-care as reminders. It was found in the present study that only $48 \%$ of the students were aware of National Accreditation Board of Health (NABH) which stress upon impending knowledge regarding this topic of current importance.

The study showed the knowledge among the medical students regarding hand hygiene practices was moderate $(363 / 557,65 \%)$. Only $2 \%$ (11/557) had good knowledge regarding hand hygiene. There is a lack of attention given to the teaching of hand hygiene practices in the Indian medical training curriculum. If there is no curriculum set with hand hygiene concepts and skills, students might end up by developing faulty hand hygiene practices. Hence, it is very much essential to include training in hand hygiene practices both theoretically and practically in the undergraduate level itself, as it helps in reducing the Health-care associated infections in future and to improve the patient care.

\section{Acknowledgements}

We thank the institute Bangalore Medical College and Research Institute and the medical students who participated in this study.

\section{References}

1. Boyce $\mathbf{J}$ M and Pittet D, Guideline for hand hygiene in health-care settings. Recommendations of the healthcare infection control practices advisory committee and the HICPAC/ SHEA/APIC/IDSA hand hygiene task force. Morbidity and Mortality Weekly Report, 2002; 23(12):S3-S40.

2. Pittet D, Allegranzi B, Boyce J. World Health Organization World Alliance for Patient Safety First Global Patient Safety Challenge Core Group of E. The World Health Organization Guidelines on Hand 
Hygiene in Health Care and their consensus recommendations. Infect Control Hosp Epidemiol. 2009; 30(7):611-22.

3. Longtin Y, Sax H, Schneider AF. Videos in clinical medicine. Hand hygiene. N Engl J Med. 2011 Mar 31; 364(13).

4. Tibballs J. Teaching hospital medical staff to hand wash. Med J Aust 1996; 164 (7): 395-98.

5. Sax H, Allegranzi B, Uckay I, Larson E, Boyce J, Pittet D. My five moments for hand hygiene. A user-centred design approach to understand, train, monitor and report hand hygiene. J Hosp Infect. 2007;67:9-21.

6. Erasmus V, Brouwer $\mathrm{W}$, van Beeck EF, Oenema A, Daha TJ, Richardus JH, et al., A qualitative exploration of reasons for poor hand hygiene among hospital workers: lack of positive role models and of convincing evidence that hand hygiene prevents crossinfection. Infect Control Hosp Epidemiol. 2009; 30(5):415-9.

7. Jang $\mathrm{JH}, \mathrm{Wu} \mathrm{S}$, Kirzner $\mathrm{D}$, Moore $\mathrm{C}$, Youssef G, Tong A, et al., Focus group study of hand hygiene practice among healthcare workers in a teaching hospital in Toronto, Canada. Infect Control Hosp Epidemiol. 2010; 31(2):144-50.

8. WHO: The Burden of health care- associated infection worldwide. A summary. Available from: http://www.who.int/gpsc/country_work/sum mary_20100430_en.pdf. (Last accessed on 2018 Nov 24).

9. WHO Guidelines on Hand Hygiene in
Health care (Advanced draft): A Summary. World Health Organization; 2009. Available from: http://www.who.int/patientsafety/events/09/ HH_en.pdf.

10. Nair SS, Hanumantappa R, Hiremath SG, Siraj MA, Raghunath P. Knowledge, attitude, and practice of hand hygiene among medical and nursing students at a tertiary health care centre in Raichur, India. ISRN Prevent Med. 2014; 1: 1-4.

11. Kamble VS, Biradar SM, Takpere A, Reddy S. Knowledge of hand hygiene practices among students of ESIC medical college, Gulbarga, Karnataka, India. Int J Community Med Public Health 2016; 3: 948.

12. Nabavi M et al., Knowledge, Attitude, and Practices Study on Hand Hygiene Among Imam Hossein Hospital's Residents in 2013. Iran Red Crescent Med J. 2015 October; 17(10):1-8.

13. Prabhakumar D, Chakravarthy M, Nayak S, Hosur R, Padgaonkar S, Harivelam C, et al., Knowledge levels of medical students about hand hygiene. J Nat Accred Board Hosp Healthcare Providers 2016; 3: 27-31.

14. Thakker VS, Jadhav PR. Knowledge of hand hygiene in undergraduate medical, dental, and nursing students: A cross sectional survey. J Family Med Prim Care 2015; 4: 582-6.

15. Modi et al., Hand Hygiene Practices Among Indian Medical Undergraduates: A Questionnaire-Based Survey. Cureus 2017; 9(7): e1463. DOI 10.7759/cureus.1463.

\section{How to cite this article:}

Bhavana, C., Jyoti S Kabbin and Ambica, R. 2019. Knowledge Levels of Medical Students about Hand Hygiene Practices in a Tertiary Hospital, Bangalore. Int.J.Curr.Microbiol.App.Sci. 8(03): 627-631. doi: https://doi.org/10.20546/ijcmas.2019.803.077 